\title{
Timing and size of daily pollen meals eaten by adult females of a solitary bee (Nomia melanderi) (Apiformes: Halictidae)
}

\author{
James H. CANE ${ }^{1}$, Heidi E. M. DoBson ${ }^{2}$, Brendan Boyer ${ }^{2,3}$ \\ ${ }^{1}$ USDA-ARS Pollinating Insect Research Unit, Utah State University, Logan, UT 84322-5310, USA \\ ${ }^{2}$ Department of Biology, Whitman College, Walla Walla, WA 99362, USA \\ ${ }^{3}$ Department of Biology, San Diego State University, San Diego, CA 92182, USA
}

Received 23 December 2015 - Revised 10 March 2016 - Accepted 24 March 2016

\begin{abstract}
Pollen feeding by solitary bees has been studied mainly with their larvae, overlooking pollen feeding by adults. To address this knowledge gap, we determined the amounts and temporal (daily and lifetime) schedules of pollen consumption by freely nesting, adult females of the alkali bee (Nomia melanderi, Halictidae). Nesting females of known ages were taken at different hours of the day from nesting aggregations managed for alfalfa pollination in southeastern Washington State (USA). Each dissected bee was visually scored for pollen fill of the crop, midgut, and hindgut; we also quantified the crop's pollen capacity. Our dissections of 188 bees show that adult females ate pollen daily for at least the first 2 weeks following emergence. Most bees ( $85 \%$ ) had pollen boluses in one or more gut regions, indicating active pollen feeding. Pollen masses were most likely in the midgut; the daily volume consumed usually filled both the crop and midgut at least once. Full crops contained 34,000 alfalfa pollen grains, equivalent to $<20 \%$ of a full scopal load and $0.8 \%$ of the pollen in a nest provision. Proportionately more females ate pollen as the day progressed, indicated by pollen masses in the crop. By early evening, crops of all bees were filled with pollen. Our study reveals the dietary importance of regular pollen feeding for nesting adult female solitary bees, and not just their larvae, with implications for bee foraging ecology, dietary physiology, reproduction, toxicology, and pollination ecology.
\end{abstract}

Apiformes / Apoidea / bees / Hymenoptera / foraging

\section{INTRODUCTION}

Most bees depend entirely on dietary nectar and pollen for their sustenance, growth, and development. The sugars of ingested nectar are the primary source of energy for both adults and larvae of all bees, whereas pollen provides all essential amino acids, some lipids (i.e., sterols), vitamins (Schmidt and Buchmann 1985; Roulston and Cane 2000), and other chemicals central to

Corresponding author: J. Cane,

Jim.Cane@ars.usda.gov

Manuscript editor: Stan Schneider bee health (Mao et al. 2013; Brunner et al. 2014). The manner in which pollen is incorporated into the diet of adults contrasts among bees, especially between eusocial and solitary species.

Much of what we know about pollen consumption and digestion by adult bees comes from research with the honeybee (Apis mellifera, Apidae). For this highly eusocial bee, adults differ in their pollen usage, depending on an individual's caste (workers versus queen), age, and gender. Worker bees progress through different tasks as they age (temporal polyethism), with correspondingly different needs for pollen. Young nurse bees consume massive amounts of pollen from which they synthesize the nutritious "jelly" secretions (from the hypopharyngeal glands) that are the sole food of queens and young worker larvae (Dietz 
1975; Crailsheim et al. 1992). Older honeybees shift to foraging, eating far less pollen that they digest less efficiently (Szolderits and Crailsheim 1993; Hrassnigg and Crailsheim 1998). Workers of several representative eusocial stingless bee species (Meliponini) also gorge on pollen to produce dietary glandular secretions that they feed to their larvae and queen(s), but their egg-laying queens can also consume pollen directly (Zerbo et al. 2001; Ueira-Vieira et al. 2013). Primitively eusocial bumble bees (Bombus spp., Apidae) are less specialized, as all adults (workers, queens, and males) consume pollen. Their workers progressively feed pollen or regurgitated food (pollen and generally nectar) to larvae (Alford 1975; Goulson 2003). The simplest dietary life-history characterizes many less social species and all nonparasitic solitary bees. Each female solitary bee makes her own nest. Instead of progressively feeding larvae, progeny are given a cached mass provision of blended pollen and nectar (or oils) collected by the nesting female (Michener 1974).

Larvae, not adults, are the focus of most pollen feeding reports for solitary bees. In early works with adult solitary bees, Bischoff (1927) and later Kugler (1970) and Schremmer (1972) included Xylocopa (Apidae) in the "crop collector" bees, which carry pollen internally in the crop (e.g., Hylaeus species) rather than externally (Thorp 2000). Despite having very hairy legs to carry pollen, they observed that Xylocopa often also have pollen-filled crops as large as a small pea. Xylocopa also have well-developed maxillary "pollen combs" to aid ingestion of pollen (Jander 1976). Interestingly, none of those three authors considered that adult Xylocopa bees might consume pollen to satisfy their own nutritional needs.

In a pioneering comparative study of pollen consumption by adult solitary bees, Taniguchi (1956) dissected 500 females and males of 40 Japanese species (15 genera in Andrenidae, Apidae, Colletidae, Halictidae, Megachilidae) collected from flowers. He noted pollen in the crop, midgut, or hindgut; ovary development; age (wing wear); and presence of scopal pollen. All bees bearing scopal pollen (hence nesting) also had pollen in their digestive tracts, particularly in the midgut and hindgut, clear evidence that adult bees eat and digest pollen. Only males, or females of cuckoo species, lacked gut pollen. Taniguchi concluded that nesting female bees regularly eat pollen.

Subsequently, several studies mention adult pollen consumption by noneusocial bees. In primitively social bees that mass-provision nest cells, Ordway (1966) observed pollen in crops of dissected queens and nonreproductive females of two Augochlorella spp. (Halictidae) but not pollen foragers. Gerling and Hermann (1978) reported that digestive tracts of Xylocopa virginica are laden with pollen early in the spring flight season. Regarding just solitary bees, Käpylä (1978) identified pollen from guts of female and male museum specimens of five Megachilidae species, Camargo et al. (1984) mentioned seeing small amounts of pollen in the crops (and possibly midguts) of female Oxaea flavescens (Oxaeidae), and Rezkova et al. (2012) reported crop regurgitate of pollen-carrying female Andrena vaga (Andrenidae) to contain pollen mixed with nectar (which they thought was destined for the provision). Schäffler and Dötterl (2011) saw newly emerged females and males of Macropis fulvipes (Melittidae) eating pollen at flowers. Together, these brief reports indicate pollen feeding by adult solitary bees, but without insight as to frequency, quantity, or temporal pattern.

Daily occurrences of pollen feeding by adult solitary bees were first alluded to by Lind (1968) who noted that female Dasypoda plumipes (Melittidae) returning to the nest always carried pollen except on the very last trip of the day, which he interpreted as being a "feeding trip" for the adult female rather than for nest provisioning. Based on similar premises, Michener (1974) incorporated pollen consumption at flowers in his diagram of material flow in solitary bees. Lind's concept of feeding trips has since been inferred from field observations of Perdita portalis (Andrenidae) (Danforth 1991) and Melissodes rustica (Apidae) (Cameron et al. 1996) and confirmed for several species by dissections of females returning to the nest (Danforth 1989, 1990; Visscher and Danforth 1993). They bore no scopal pollen, but their crops contained nectar mixed with variable amounts of pollen. Isenberg et al. (1997) examined crop contents of female M. rustica (Apidae) at two times of day. Females' 
crops contained little pollen at midday, when females provisioned nests, whereas after the day's last trip, crops were distended with pollen (regardless of whether bees carried scopal pollen). These findings demonstrate that adult female solitary bees periodically consume pollen.

Evidence from various sources link pollen consumption by adult female bees to ovarian development and nesting. Taniguchi (1956) concluded from his dissections of diverse bees that most young (unworn) females eat pollen upon emergence, as was observed in the field for M. fulvipes by Schäffler and Dötterl (2011), reflecting their need to mature ovaries. He found that female cleptoparasitic bees, which rarely had crop pollen, had ovaries that appeared fully developed at emergence, and that in bivoltine Halictus species, the autumn (second and hibernating) generation ate little pollen until nest construction the following spring. Likewise, pollen-filled guts of $X$. virginica appeared to be associated with ovary development (Gerling and Hermann 1978) as were the crops of variously aged (with differently sized ovaries) social halictine bees that were dissected extensively for other purposes (Michener 2007). Wuellner (1999) linked pollen feeding to egg production by Dieunomia triangulifera (Halictidae), comparing dissected crops of young females (unworn wings, undeveloped ovaries, searching nest site) with those of older nesting females.

In the most conclusive study, Richards (1994) showed experimentally that pollen consumption is key to early ovarian development by Megachile rotundata (Megachilidae). When newly emerged females were deprived of pollen (but provided honey or sugar water), their oocytes failed to enlarge; either fat body stores were inadequate or something in pollen cues ovarian development. Considering that solitary bees' eggs are comparatively huge for an insect (Iwata and Sakagami 1966) and packed with proteins and lipids (Wheeler 1996), it is not surprising that female solitary bees emerge with inadequate reserves to mature eggs without ingesting substantial quantities of pollen.

Adult females of many solitary bees are burdened with an additional daily drain on lipid stores, namely glandular secretions used in nest construction. Prior to oviposition, many groundnesting bees (e.g., Colletes, Andrena, Nomia, Anthophora ) discharge a lipid-rich secretion from their voluminous abdominal Dufour's gland, typically to waterproof nest cell walls (Cane 1981) and, rarely, to fortify larval provisions (Cane and Carlson 1984; Norden et al. 1980). This daily outlay of Dufour's gland secretion by many species, together with ubiquitous egg-laying demands, must impose nutritional costs on mother solitary bees that can be offset only by periodic pollen feeding.

The objective of this study was to improve our understanding of the temporal schedule and extent of pollen consumption by adult female solitary bees. Using freely nesting female alkali bees (Nomia melanderi) from a range of known ages, we characterized daily and lifetime schedules of pollen consumption and estimated the pollen capacity of the crop.

\section{MATERIALS AND METHODS}

We studied nesting $N$. melanderi females during June and July 2010 at three of the many managed nesting aggregations near Touchet, in the Walla Walla Valley in southeastern Washington. Alkali bees have been managed there for $50+$ years to pollinate alfalfa for seed production (Cane 2008). This species is polylectic, protandrous and, in this northern part of its range, univoltine.

\subsection{Bee collection}

To obtain adult nesting females of a range of known ages, we daily located newly initiated nests to mark on the day that they appeared at the start of the bee's flight season. Bohart and Cross (1955) observed that female $N$. melanderi commence nesting on their day of emergence, and remain with the same nest for at least two weeks. An active new nest is recognized by a small damp soil heap (tumulus) and periodic appearance of the resident female pushing out fresh soil from below. To further confirm that a fresh moist tumulus indicated nest initiation (rather than emergence), we punched a grid of 176 bee-sized cylindrical 8-cm-deep holes into undisturbed soil. By the next day, $56 \%$ had moist tumuli, all associated with new nests. We concluded that females associated with a fresh new tumulus were 
1-day-old adults. Thereafter, bees of desired age could be collected on specific dates from marked newly started nests.

During June 19-23 (after protandrous emergence of males had begun), delimited areas of $10-15 \mathrm{~m}^{2}$ at each aggregation were monitored daily for fresh tumuli of new nests. New nests were discretely marked using small toothpick flags that were color-coded for date. This method disturbed females less than collecting, narcotizing, and paint-marking them. Over 1000 new nests were marked over the 4 days. From June 23 to July 5 , we collected females of ages 1-15 days old at their marked nests on days when fair weather allowed them to forage. All collected bees were transferred to chilled vials, held on ice for $<2 \mathrm{~h}$, and then frozen $\left(-15^{\circ} \mathrm{C}\right)$ at the lab until dissected, often on the same day.

To characterize diurnal patterns in pollen consumption, females issuing from marked nests were caught across all daylight hours, from 0820 to 1920 hours. They were grouped into one of four different diurnal time periods: (1) early morning -within $5 \mathrm{~h}$ of local sunrise (to 1035 hours PDST), which included the first flights of the day; (2) late morning - from then to solar noon (1252 hours); (3) afternoon - from then to $3 \mathrm{~h}$ before sunset (1748 hours); and (4) early eveningfrom then until sunset, which included the last flights of the day. These groupings have similar sample sizes ( $n=45-50$ dissected bees).

Bees were collected by slightly different methods, depending on their diurnal activity. Thus, for morning collections (especially early morning), clear plastic cups were placed over as many marked nests as possible to capture females leaving for their first or second flights of the day. For late morning, afternoon, and some early evening collections, cups were placed over marked nests, and females were captured as they either returned from a foraging trip and hovered about the cup, or flew up into the cup en route to their next foraging trip. For evening collections, when females had returned from what seemed to be their last foraging flight, resident females were provoked to nest defense by inserting a grass stem down the nest tunnel to patiently lure them to the nest entrance for capture. Lastly, some additional female bees of undetermined age were also collected flying over the nest site surface mid-morning during the first 2 weeks of flight activity to bolster sample sizes for some hourly time periods.

\subsection{Assessment of pollen in alimentary tract}

Frozen females were dissected under a stereomicroscope. Each thawing bee was covered with tap water and its abdominal (metasomal) terga were clipped off or pulled to one side to reveal the entire alimentary tract (gut), from the crop to the rectum (Figure 1). Each gut was carefully isolated from other organs and tissues to score its content of pollen (see below). Dissected guts were then preserved in $70 \%$ ethanol.

The pollen fill of the fresh gut was visually scored for each of the three regions of the alimentary tract: (1) crop (main part of foregut), (2) midgut, and (3) hindgut (ileum + rectum). For the crop, both nectar and pollen presence were noted. Nectar content varied among bees, as evident from the degree of distension of the crop with clear fluid. Pollen in the crop (pale yellow in alfalfa) formed an opaque suspension and, consequently, was scored based on the opacity and relative volume of the suspension. In the midgut and rectum, pollen was typically clumped into one or more opaque masses (boluses) of varying lengths (midgut) or diameters (rectum).

To visually score the quantity of pollen in each gut region, four categories of pollen fill were used: empty $=$

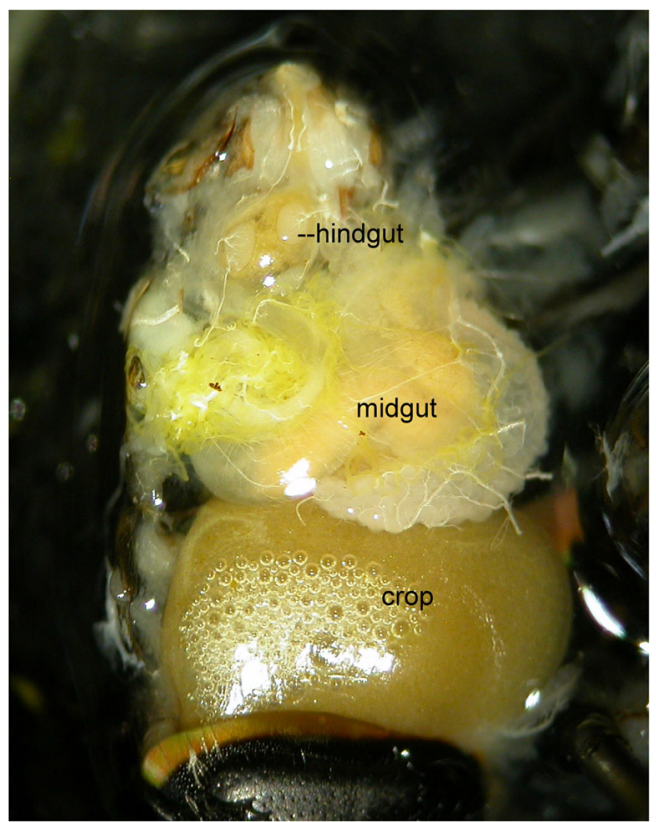

Figure 1. Dorsal view of a female's dissected abdomen of $N$. melanderi . Terga have been pulled aside to reveal the full crop, midgut, and hindgut. 
no visible pollen grains or boluses; sparse = sparsely dispersed grains, individually visible; some $=$ crops opaque with a pollen suspension, midguts containing one to two distinct and separate cylindrical boluses, hindguts with several spherical boluses; and full = crops fully distended with a solid opaque pollen suspension, mid- and hindguts largely filled with pollen boluses. Mass combines the pollen fill categories of "some" and "full" (= presence of one or more pollen masses) of a gut region to represent an intentionally eaten pollen meal.

\subsection{Quantifying pollen grain capacity of full crops}

The numbers of pollen grains contained in a full crop were counted for those bees whose distended crops were filled with an opaque pollen suspension. Such crops were tautly turgid and nearly spanned the width of the anterior abdominal cavity. The intact crop was separated and lifted from the rest of the gut and then torn open or slit over a $0.6-\mathrm{mL}$ centrifuge tube filled with $0.2-0.4 \mathrm{~mL}$ of $70 \%$ ethanol (volume matched to the crop's distension). The crop membrane was vigorously swirled in the ethanol to remove any adhering pollen and discarded after microscopically confirming that it had been emptied. The tube contents were agitated (using a Lab Line Super-Mixer or ultrasonicator) until the pollen suspension appeared uniform $(<5 \mathrm{~s})$. Two 10$\mu \mathrm{L}$ aliquots were sequentially pipetted from the agitated suspension and placed in separate chambers of a hemocytometer slide. This sampling procedure was replicated three times per sample. For each replicate sample, all pollen grains viewed microscopically at $100 \times$ were counted in the four corner grids of both chambers (= eight grids total). To calculate the total number of pollen grains in a crop, the average count of the three replicates was divided by $0.0008 \mathrm{~mL}$ (= total volume occupied by eight grids) and multiplied by the original volume of the pollen-ethanol suspension (there was too much fine particulate for a particle counter).

For comparative purposes, pollen was also quantified for both (1) full scopal loads of two returning foragers and (2) 33 intact provision masses. A pollencollecting female's pair of clipped-off hind legs or a ball of provision (minus its egg) was placed individually in a precleaned glass bottle with $50 \mathrm{~mL}$ of filtered particlefree ethanol, and dispersed by ultrasonication for $120 \mathrm{~s}$; for scopal loads, legs were visually checked for remnant pollen and then removed. Two $1-\mathrm{mL}$ aliquots were withdrawn from a bottle's agitated suspension, and each was resuspended in $50-\mathrm{mL}$ ethanol. Then, $25 \mathrm{~mL}$ of each of the two agitated subsamples was counted using a HIAC/ROYCO $®$ particle counter equipped with an ABS sampler.

\subsection{Statistics}

To test if nesting females consume pollen at regular diurnal time periods, our dependent variable consisted of the incremental categories of pollen fill, from empty to full, for each gut region. The proportions of dissected females scored for each pollen fill category in the three alimentary tract regions were grouped into four diurnal time periods and two groups, being young (1-3 days) and older (7-15 days) nesting bees. The data were therefore categorical and incrementally ordered both by pollen fill and by diurnal periods or age groups, for which logistic regression is appropriate. Binary data were analyzed by logistic regression using the SAS "Logistic" module to generate maximum likelihood estimates (Allison 2012). The changing proportions of pollen fill for dissected females were compared for sequential time periods using an adjacent-categories model in the SAS "CatMod" module, specifying the "Alogit" option where appropriate (Allison 2012). Diurnal patterns in pollen fill were tested separately for each of the three regions of the alimentary tract. If the overall effect of time was significant in the maximum likelihood ANOVA $(p<0.05)$ and convergence criteria met for the model, then odds ratios were calculated from weighted least squares estimates for pairs of adjacent time periods that differed significantly for a given category of pollen fill. Numerical data are given as the mean \pm standard error.

\section{RESULTS}

A total of 188 female bees of various ages were collected at different hours of the day and later dissected. We collected returning foragers from 0820 to 1900 hours, adding some more evening bees that we extracted from their nests. Of these, 159 bees were of known age and 29 bees of undetermined age. Among the aged bees, we had far more newly nesting (1-3-day-old; $n=110)$ than 1 -week-old $(n=23)$ and 2-weekold $(n=26)$ females. Obtaining enough older females was challenging due to natural attrition, possible nest supercedure, and our diminishing 
confidence for an individual bee's association with an older marked nest amid many thousands of crowded nests.

Most nesting female alkali bees had visible masses or suspensions of pollen somewhere in their alimentary tracts (Figure 1). Pollen masses were present in the crops and midguts of similar majorities of females (63 and $76 \%$, respectively); likewise, sparse pollen suspensions were similarly represented in these two gut regions (Figure 2). In contrast, fewer hindguts $(44 \%)$ had pollen masses; hindguts more often contained only sparse pollen compared with either crops $(p=0.005)$ or midguts $(p=0.001)$ (Figure 2). Nearly one third (55 bees, $29 \%$ ) of all dissected females had pollen masses ("some" and "full" categories) throughout their alimentary tracts, from crop through midgut to hindgut. Considering the pollen fill categories "sparse" and "no pollen," only $15 \%$ of all dissected females lacked evidence of active pollen feeding (no pollen masses anywhere in their alimentary tracts). Because midguts were more likely to be filled with masses of pollen than other gut regions, midguts were thus more indicative of active pollen consumption.

\subsection{Pollen consumption throughout the season (bee age)}

During their first 2 weeks of nesting following emergence, female bees regularly consumed

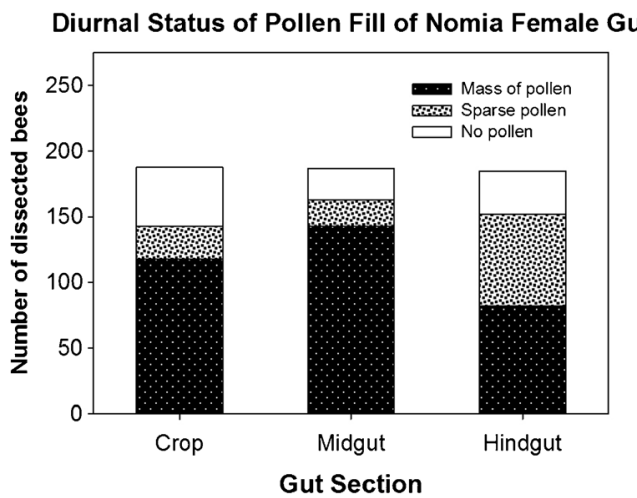

Figure 2. Pollen fill status of each alimentary tract region of all 188 dissected nesting female $N$. melanderi, grouping "some" and "full" categories as a "mass of pollen". pollen, as was evident from the large proportion of both young and old dissected bees that contained masses of pollen, especially in the midgut (Figure 3). The general proportions of pollen fill among the three gut regions of young females ( $1-3$ days old, $n=110$ ) persisted among even 13-15-day-old females $(n=26)$, indicating that females continued to regularly eat pollen for at least the first 2 weeks of their adult nesting lives. Few of the 110 young females $(8 \%)$ lacked pollen throughout their alimentary tracts (that is, most contained a pollen meal). In contrast, significantly more ( $24 \%$ ) older females ( $>6$ days) were largely void of pollen $\left(n=49, \chi^{2}=6.9\right.$, $p \leq 0.008$ ). This 3 -fold difference with age, however, was confounded with the hour of collection, as most old females were taken in the mornings, when pollen feeding was less likely (see below). Importantly, nearly $75 \%$ of even the older females had pollen masses somewhere in their alimentary tracts, further evidence that females continued to consume daily pollen meals as they aged.

\subsection{Pollen consumption patterns during the day}

Nesting female alkali bees did not consume pollen regularly over the course of a foraging day, which we divided into four diurnal time periods. We interpret pollen masses in the crop to indicate a recent feeding event, whereas pollen boluses passed on into the midgut and later the hindgut reflect a pollen meal eaten earlier that day (or the previous evening if no defecation flight had since been possible).

As a day progressed, females were increasingly likely to have pollen masses somewhere in their guts, from $73 \%$ bees at early morning to all sampled bees by evening (Figure 4). Conversely, bees with sparse or no pollen anywhere in their alimentary tracts were more common in the first half of the day. Bees collected in the afternoon (1253-1748 hours) and evening (after 1748 hours) periods constituted 31 and $40 \%$, respectively, of the 55 bees that had pollen masses throughout their entire gut (crop through hindgut). Pollen masses in both the crop and the hindgut likely reflect two different pollen meals eaten in the same day (Figure 4). From this perspective, nearly 


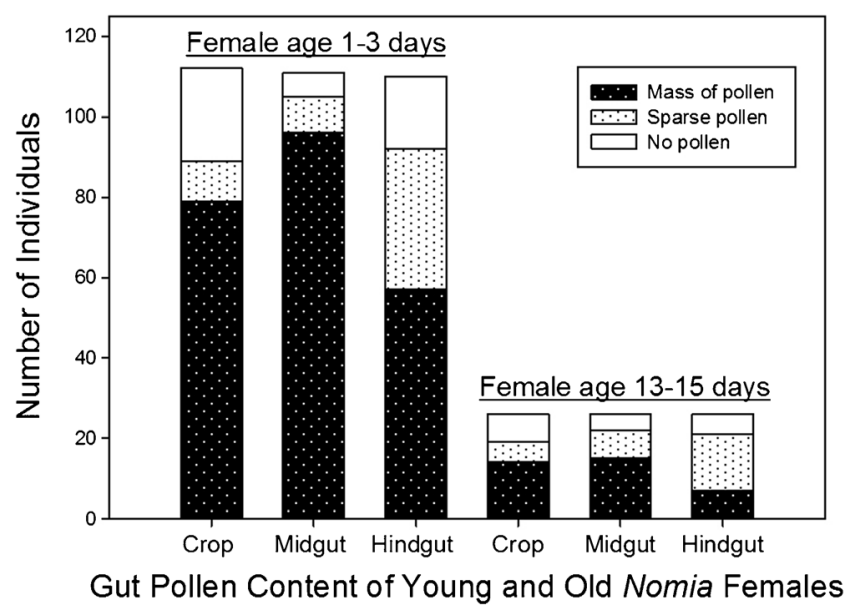

Figure 3. Comparison of the pollen fill status of each alimentary tract region in 110 young, recently emerged N. melanderi (aged 1-3 days) and 26 old nesting females (aged 13-15 days).

three fourths of the dissected afternoon and evening bees had actively eaten pollen both recently as well as earlier in the day.

\subsubsection{Crop pollen}

It is evident from the proportions of bees with pollen masses in their crops that females were actively feeding on pollen periodically throughout the day (Figure 5a). However, the likelihood of crop pollen fill changed as the day progressed $\left(\chi^{2}=50.2, p \leq 0.001\right)$. Bees' crops were most likely to be completely devoid of pollen in the early morning $(47 \%)$, when bees started their foraging days. Crops of females were increasingly likely to be fuller with pollen with each later daily time block, thus, early morning < late morning < afternoon $<$ evening $\left(\chi^{2}\right.$ range $11.8-16.5$, $p \leq 0.006$ or less).

Before solar noon, only some females had pollen masses ("full" + "some" fill categories) in their crops (36 and $48 \%$ of early and late morning bees, respectively) (Figure 5a). By afternoon, three fourths of females that we dissected had a pollen meal in their crops. Later still, nearly all (93\%) crops of evening bees were filled with pollen masses. The proportion of females with a crop full of pollen approximately doubled with

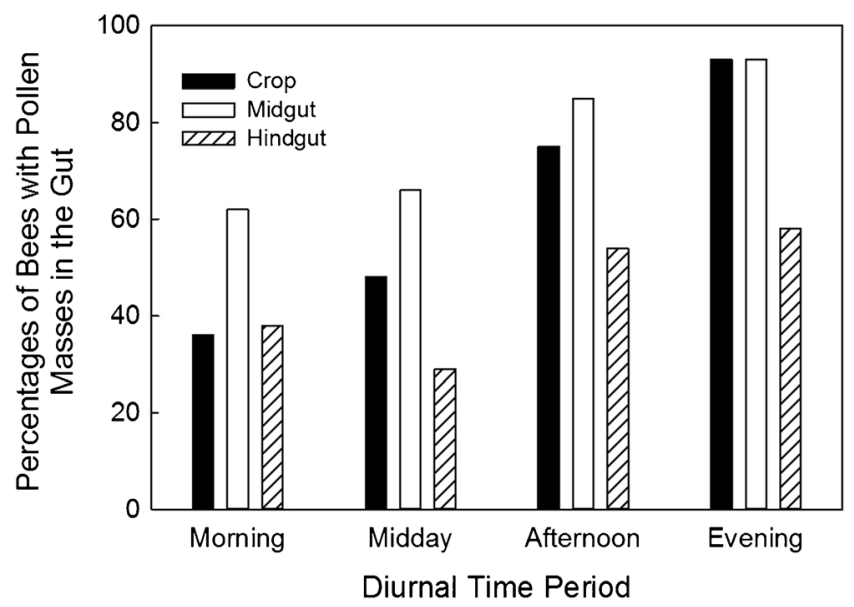

Figure 4. Diurnal patterns in the percentages of 188 dissected nesting female Nomia melanderi that had evidence of pollen meals (grouping "some" and "full" pollen fill categories) by each gut region across the four periods of the day. 
a

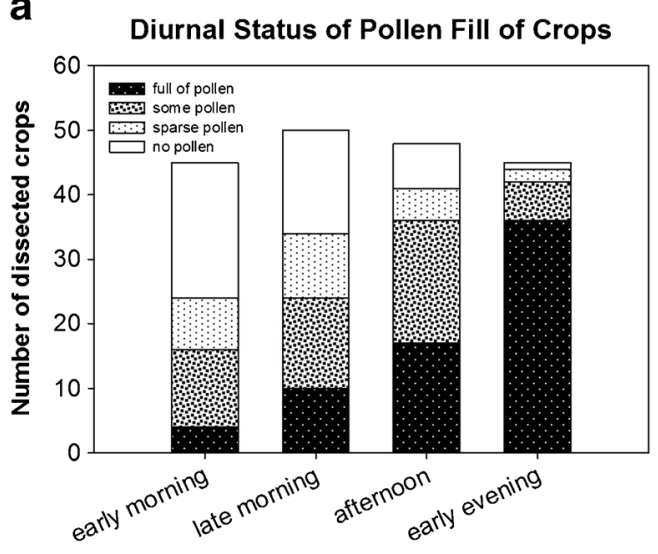

Diurnal time period

b

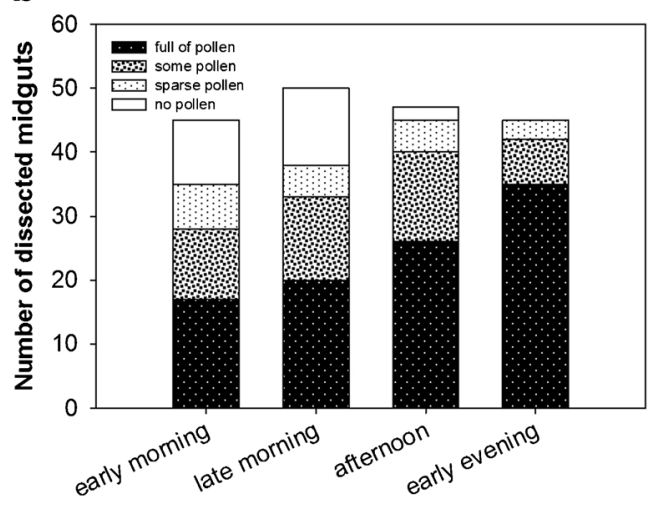

Diurnal time period

\section{Diurnal Status of Pollen Fill of Hindgut}

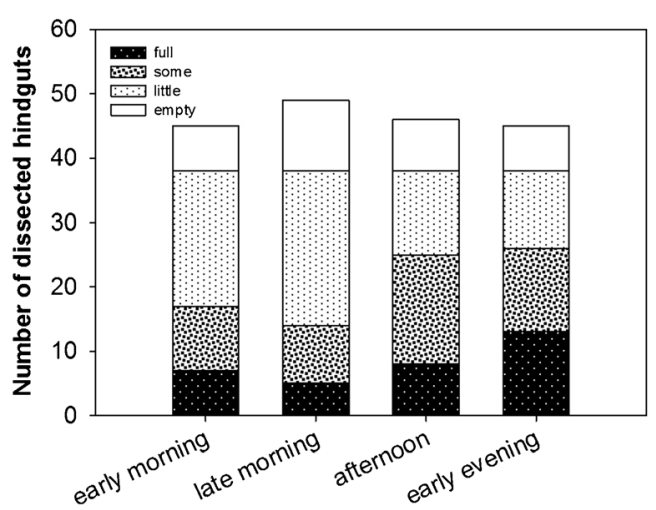

Diurnal time period

Figure 5. Diurnal patterns in the pollen fill status of a crops, $\mathbf{b}$ midguts, and $\mathbf{c}$ hindguts of all 188 dissected nesting females of $N$. melanderi . each ensuing time period, from only $9 \%$ of bees having crops full of pollen in early morning to $20 \%$ in late morning, $35 \%$ in the afternoon, and finally to $80 \%$ in the evening.

Regardless of age, almost all females collected in the evening had crops containing masses of pollen (Figure 6). Of the 33 newly emerged young nesting females (1-3 days old) collected in the evening, $94 \%$ had pollen masses in their crops. This feeding pattern continued unabated with older females. We had far fewer 1-week-old (78 days old, $n=4)$ and 2-week-old (13-14 days old, $n=10)$ females to dissect that we had collected in the evening. All but one of these 14 older bees also had crops filled with masses of pollen in the evening (Figure 6). It is evident that nesting female $N$. melanderi regularly ate a daily evening pollen meal throughout much (if not all) of their nesting lives.

\subsubsection{Midgut pollen}

As with the crop, the pollen fill of females' midguts differed significantly among time periods $\left(\chi^{2}=22.8, p \leq 0.008\right)$. Their midguts were increasingly likely to be fuller with pollen as the day progressed: early morning < late morning < afternoon $=$ evening $(p \leq 0.05)$ (Figure $5 b)$. Few bees lacked pollen in their midguts; most of these bees came from the first half of the day ( 22 and $24 \%$ in early and late morning, respectively). Only $4 \%$ of afternoon bees lacked midgut pollen.

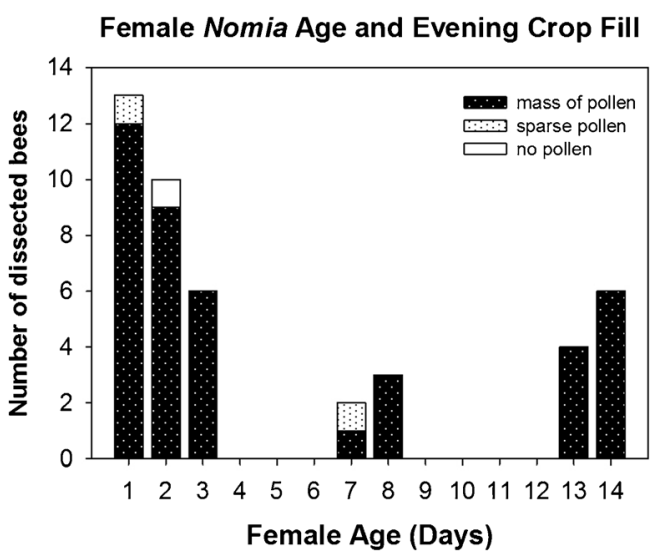

Figure 6. Active evening pollen consumption, as indicated by the presence of one or more pollen masses in the females' crops during their first 2 weeks of nesting. 
Every evening bee had one or more pollen boluses in its midgut, up from $62 \%$ of females taken in early morning.

\subsubsection{Hindgut pollen}

The hindgut differed from the other gut sections for its diurnal patterns of pollen fill (Figure 5c). The overall logistic regression model for time blocks and pollen fill fit the data well (Pearson $\chi^{2}$ of residuals $=5.9$ ), but in stark contrast with crops and midguts, time effects were only marginally significant for hindguts $(p=0.049)$. Only the late morning and afternoon time blocks differed significantly ( $p=0.008)$. Half the hindguts of these late morning bees contained at most sparse pollen, more than any other combination of gut section and time block. Among the 38 afternoon and evening bees with little or no pollen in their hindguts, three fourths had pollen masses in both their crops and midguts, indicating pollen meals from the same day that had not yet reached the hindgut. Relatively few bees had hindguts full of pollen (Figure 5c). However, in hindsight, our earliest morning samples missed taking bees directly from their nests, before they had any opportunity for a first flight to defecate what we now know would have been the digested remains of the previous evening's pollen meal.

\subsection{Comparative counts of pollen in crops, scopae, and nest provisions}

Full crops of nesting females were turgid and voluminous (Figure 1), filled with a large opaque mass of pollen. Dimensions of 37 full crops averaged $4.5 \pm 0.13 \mathrm{~mm}$ long and $3.5 \pm 0.1 \mathrm{~mm}$ wide (average volume $=34 \mathrm{~mm}^{3}$ ). These full crops held $33,953 \pm 2440$ alfalfa pollen grains $(n=36$ crops, range 12,500-63,000 grains). Seven crops that we scored as visibly empty of pollen contained only $3119 \pm 656$ pollen grains.

Scopal loads and provision masses contained far more pollen than did crops. Two returning females carried 127,000 and 271,000 pollen grains in their scopal leg loads, nearly 4-fold more pollen than a full crop. Completed, uneaten provision masses of $N$. melanderi $(n=33)$ consisted of 4,068,000 $\pm 184,000$ alfalfa pollen grains, or over 100 -fold more pollen than a full crop.

\section{DISCUSSION}

This is the first study to extensively and systematically document and quantify hourly, daily, and lifetime patterns of adult pollen feeding by nesting females of a solitary (nonsocial) bee. Examining the pollen fill of all three major regions of the alimentary tract proved invaluable for complementary insights into the timing and amounts of pollen consumed during feeding bouts. We found that nesting female $N$. melanderi consumed pollen several times daily. Evidence of pollen consumption was observed throughout the foraging day, although pollen meals became more likely as each day progressed. By evening, nearly all females had abundant pollen in both their crops and midguts, suggesting that they had eaten one recent pollen meal plus one (or more) meals earlier in the day. The few earlier studies, which only examined crop fill, reported just late-day "feeding trips" during nesting (Isenberg et al. 1997; Danforth 1990, 1991). We found that female $N$. melanderi began gorging on pollen within hours of emergence and continued to eat daily pollen meals most, and possibly all, of their adult lives. Such regular pollen feeding highlights the importance of pollen, not just nectar, in the diet of adult solitary bees. These results support Richard's (1994) assertion that dietary pollen underpins a female solitary bee's ability to reproduce and, extrapolating from honeybee studies (Mao et al. 2013; Brunner et al. 2014; Wang et al. 2014), may generally extend bees' longevity and maintain a healthy immune system. Given the magnitude and regularity of pollen feeding by adult female N. melanderi, combined with Taniguchi's (1956) broad taxonomic survey, we expect similar ingestion patterns from nesting females of other solitary bee species. Daily pollen feeding by female solitary bees has implications for their egg-laying capacities, health, pollination ecologies, carrying capacities in cropland, and exposure risks to pesticides present with pollen.

For at least the first two weeks following emergence, nesting alkali bees daily consumed pollen meals large enough to partially to fully fill their crops and midguts, a pollen amount that we estimate equals 2-3 crop refills daily. Our findings explain Taniguchi's (1956) observation that 
pollen-bearing females of diverse solitary bee species always had pollen in the midgut and/or rectum, regardless of observed ovarian maturity or relative age (wing wear). Taniguchi encountered bees with pollen-filled crops less often, possibly due to the (unreported) hours that he collected them. To characterize adult pollen consumption, our study reveals the importance of the daytime hour and the need to examine the entire alimentary tract and not just the crop.

Although the crop is often the easiest gut section to study, crop pollen reveals only recent feeding, as its pollen passes relatively quickly into the midgut (30 min for worker honeybees) (Whitcomb and Wilson 1929; Dietz 1969; Peng et al. 1986). Once in the midgut, pollen progresses slower while being digested. For honeybees, pollen arrives at the hindgut 2-15 h after ingestion (Peng et al. 1986; Dietz 1969). Consequently, midgut pollen is evidence of a pollen meal eaten earlier the same day and, therefore, reliably indicates that day's feeding. In contrast, pollen boluses in the hindgut are less informative, since their presence reflects both much earlier feeding and also the need for a defecation flight that can be delayed by nightfall or inclement weather.

We observed distinct diurnal patterns for increasing likelihood of pollen masses in crops. This diurnal pattern was less pronounced for midguts, consistent with honey bee data that pollen lingers longer there while digesting. Pollen-filled crops likely result from one feeding trip and not from incremental ingestion of small pollen meals over several foraging trips. Females watched in observation nests consistently regurgitate nectar on growing provisions after most or all foraging trips, as reported for N. melanderi (Batra 1970) and a species each of Agapostemon, Anthophora, Megachile, and Osmia (Phillips and Klostermeyer 1978; Klostermeyer and Gerber 1969; Roberts 1969; Batra and Norden 1996). Moreover, midguts were significantly more likely to contain pollen by afternoon, implying that any pollen consumed in the morning was well into the midgut within just a few hours. In contrast, the only diurnal change we saw for hindgut pollen was a tendency toward emptier hindguts by late morning, once females could fly and defecate the evening pollen meal, but before newly ingested pollen could be digested. Systematic studies on the rate of pollen passage through the gut of $N$. melanderi, akin to honeybee studies, would establish a firm reference for interpreting data on the pollen content of different gut regions in terms of the precise diurnal schedules of pollen consumption.

The probability of adult female alkali bees consuming pollen (based on visible crop contents) increased significantly as the day progressed, reaching $75 \%$ by the afternoon and $>90 \%$ by evening (Figure 5a). Pollen feeding was not restricted to day's end, as suggested for a few other ground-nesting solitary bees (Isenberg et al. 1997; Danforth 1990, 1991). We found pollen masses in $36 \%$ of the crops of nesting females caught after their first few foraging trips of the day and close to half of them by late morning (Figure 5a). Clearly, nesting females ate pollen at different hours. Some began eating early in the morning, but by evening, nearly all had crops with pollen, $81 \%$ of them full (Figure 5a). Evidently, all bees eat a pollen meal at the end of their foraging day, but many ate pollen earlier in the day, too.

Variation in the time of day when $N$. melanderi females began consuming pollen may reflect differing schedules in nest construction and provisioning and the need to regurgitate nectar carried in the crop to moisten nest provisions. It seems probable that females provisioning a nest cell would avoid feeding on pollen for their own nutritional needs, since any food in the crop would be lost during nectar regurgitation. Most $N$. melanderi in greenhouse observation nests constructed new cells overnight, spent mornings and early afternoons provisioning the new nest cell, and then oviposited and closed the cell by mid-afternoon (Batra 1970). Under field conditions, the hour of cell completion undoubtedly varies, after which females could devote their crop entirely to self-feeding. Consistent with this scenario, only toward evening were the crops of all our dissected bees filled with pollen. However, one third of our bees began eating pollen in the morning, and some pollen feeding occurred throughout the day. Sometimes females complete a nest cell the following morning (Batra 1970), after which they could eat pollen. Foraging trips in the middle of a provisioning sequence are often 
only for pollen, with final nectar additions at the end to form the final pollen ball (Batra 1970). This provides a broad time window for females to feed during the day. Detailed observations of in-nest activity would clarify how females partition time between feeding themselves and provisioning their progeny.

Waiting to ingest pollen late in the day, following cell provisioning and oviposition, incurs two potential risks for a nesting female bee. The first is floral pollen depletion. In some years or places, local bee communities will exceed carrying capacities of their floral community. When that happens, pollen will be depleted by late afternoon or evening. Such intense resource competition is especially likely on farms, where growers may overstock managed bees as insurance or to maximize pollination. When ample unvisited flowers remain in alfalfa seed fields pollinated by managed $N$. melanderi, we calculate that a female can fill her crop with pollen during just four min of foraging. But when the standing crop of pollen is exhausted, reliance on just an evening pollen meal is risky. A nesting female's second challenge is inclement weather. For the arid range of $N$. melanderi, most summer days are hot, dry, and fair. For a vernal bee, or one living where summers are colder or rainier, unfavorable weather could preclude the evening pollen meal. For all of these reasons, the occasional earlier pollen meals that we observed could be important.

For $N$. melanderi females foraging on alfalfa, pollen eating should have little effect on crop pollen depletion or overall pollination. Given that a foraging female removes about 1000 alfalfa pollen grains from each flower that she "trips" (causing the staminal column to snap up beneath her head) (Cane, unpublished), and that she trips $80 \%$ of visited flowers (Cane 2002), she should be able to acquire a crop full of pollen by visiting $<50$ virgin alfalfa flowers. The bee's crop holds only $0.8 \%$ of the pollen in the day's provision mass, so $99 \%$ of harvested pollen (and floral visits) goes to larval provisions. Summed over two weeks of active nesting, pollen eaten during the several daily pollen meals only amounts to about one third of a provision, or the pollen obtainable from about 1200 alfalfa flowers. Females' lifetime pollen eating will not contribute much additional pollination for alfalfa either, only about 1500 seeds (half of tripped alfalfa flowers set pods, each averaging 2.7 seeds) (Cane 2002). Female pollen feeding only has relevance for her own dietary needs for reproduction.

The limited capacity of an alkali bee's crop underscores the general advantage of scopal pollen transport for larval provisions. Scopae are the external hair brushes and bare pollen "baskets" bees use to transport pollen (primarily on the hind legs or under the abdomen) (Thorp 2000). A full crop of $N$. melanderi holds $<20 \%$ of the pollen in a full scopal load (34,000 vs. 200,000 alfalfa grains, respectively). Transporting pollen using the crop alone would entail 5-fold more provisioning trips for each nest cell. Under ideal conditions, she could thereby provision only two nest cells weekly. Hence, scopal pollen transport is highly advantageous for a bee. Among nonparasitic solitary bees, only Hylaeinae and Euryglossinae lack scopae: they transport pollen mixed with nectar internally in their crops (Michener 2007). Our results raise the question of how these bees manage to internally transport all the pollen they need to provision their progeny while accommodating their own dietary needs.

Conversely, it would seem advantageous for solitary female bees to always carry a pollen-rich slurry of nectar in their crops, rather than nectar alone, to regurgitate for larval provisions. However, more than half of female $N$. melanderi caught returning to their nests during morning hours had clear, nectar-filled crops. From our pollen counts, we know these to contain $<10 \%$ of the pollen capacity of a full crop. We deduce that most pollen consumption must be intentional, and therefore, females choose not to ingest pollen to regurgitate with nectar during provision assembly. Obviously, there is much to learn here, including comparison with other bee species.

Provisioning progeny predominantly with inferior or toxic pollens incurs a clear fitness cost, with no opportunity for correction. If nesting females could associate a superior pollen source with greater satiation or key gustatory stimuli, then there is the possibility for dietary selfselection (sensu Waldbauer and Friedman 1991) to guide the next day's foraging and provisioning. Several polyphagous insects (e.g., flour beetles, 
grasshoppers, cockroaches) are known to actively self-select foods to correct dietary nutrient imbalances (cited in Waldbauer and Friedman 1991; Behmer 2009). Evidence that dietary selfselection occurs in solitary bees might be found by comparing the identity of pollen in the gut (crop) or feces with that in the scopae of individual females over time.

Female solitary bees lay no more than 1-2 eggs per day (Neff 2008), a tempo that persists even when they have abundant bloom and long foraging days (Maeta and Kitamura 2005). In the absence of poor weather or sparse bloom, it appears that solitary bees' physiological ability to mature eggs limits their daily reproduction. Perhaps females are unable to eat and process enough pollen and nectar to produce additional eggs, or perhaps it is simply the time and internal space needed for vitellogenesis and embryogenesis. The different explanations will be challenging to distinguish by experimental manipulation.

Daily pollen consumption by nesting female bees engenders some previously unforeseen risks for insecticide exposure. First, those systemic insecticides requiring ingestion and found in pollen (Blacquiere et al. 2012) will be eaten daily by mother bees as well as their larvae. Second, lipophilic insecticides or carriers applied to bloom seem more likely to dissolve in oily pollenkitt, not watery concealed nectar, again to be ingested with pollen. In one case, maternal ingestion of insecticide-contaminated pollen or nectar was suspected in bee egg mortality (Hodgson et al. 2011). Toxicology assays that consider adult pollen consumption will help guide safer insecticide use around bees.

Knowing that adult solitary bees regularly ingest pollen should modify our understanding of bee-flower interactions. New directions of inquiry are opened, as well as reconsideration of earlier, more simplistic views of the associations between bees and pollen based mainly on larval diets alone. Our present study of pollen feeding by adult female $N$. melanderi needs to be extended to male and cleptoparasitic bees, and to more solitary bee species, to know how broadly such traits apply to solitary bees. Our findings also raise fundamental questions for the potential evolutionary advantages, and their mechanistic bases, that adult bee pollen feeding might have to the fitness of adult solitary bees and their progeny.

We end on a cautionary note regarding pesticide exposure risks that could result from the now evident daily pollen feeding by nesting female solitary bees. Studies evaluating the impacts of pesticides on solitary bees are not all new (Bohart and Lieberman 1949) but are increasingly sophisticated, measuring bees' exposures and responses through nectar (consumed by adults and/ or larvae) (Sandrock et al. 2014), surface contact (Waller 1969), and larval provisions (Abbott et al. 2008; Hodgson et al. 2011; Giurgius and Brindley 1974). Exposure of adult females via pollen they daily consume remains unexplored, although it will magnify a nesting female's lifetime exposure to any toxins. Quantifying the daily adult pollen meals of additional solitary bees will improve estimates of daily and lifetime insecticide dosages ingested with pollen, thereby bettering our understanding of any resultant mortality, or sublethal behavioral and physiological detriment, that some insecticides might impose directly on nesting female solitary bees.

\section{ACKNOWLEDGMENTS}

We appreciate growers Mike Buckley, Stuart Byerley, and Mark and Tim Wagoner for allowing us to use their alkali bee beds and collect their bees. Siena Picchi-Dobson contributed many patient bee dissections, Susan Durham gave informed statistical council, and Jiulina and Lisi Dobson cleaned up the study sites. Financial support was provided by the USDA-ARS and Whitman College, and a special gift from Phillip and Suzanne Moss is acknowledged. We dedicate this manuscript to the memory of the late Charles Michener, whose enthusiasm, research, and scholarship with wild bees kindled our own interest and that of so many other bee biologists cited here.

Rythme et taille des repas de pollen pris au cours de la journée par les femelles adultes d'une abeille solitaire (Nomia melanderi) (Apiformes: Halictidae)

Apoidea / solitary bee / Hymenoptera / foraging / pollen consumption / female 
Zeitverlauf und Umfang der täglichen Pollenmahlzeiten adulter Weibchen der solitären Biene Nomia melanderi (Apiformes: Halictidae)

\section{Apoidea / solitäre Biene / Hymenoptera / Futtersuche / Pollenkonsum / Weibchen}

\section{REFERENCES}

Abbott, V.A., Nadeau, J.L., Higo, H.A., Winston, M.L. (2008) Lethal and sublethal effects of imidacloprid on Osmia lignaria and clothianidin on Megachile rotundata (Hymenoptera: Megachilidae). J. Econ. Entomol. 101, 784-796

Alford, D.V. (1975) Bumblebees. Davis-Poynter, London

Allison P.D. (2012) Logistic regression using SAS: Theory and application. SAS Institute, Cary, North Carolina, USA

Batra, S.W.T. (1970) Behavior of the alkali bee, Nomia melanderi, within the nest (Hymenoptera: Halictidae). Ann. Entomol. Soc. Amer. 63, 400-406

Batra, S.W.T., Norden, B.B. (1996) Fatty food for their brood: how Anthophora bees make and provision their cells ((Hymenoptera: Apoidea). Mem. Entomol. Soc. Wash. 17, 36-44

Behmer, S.T. (2009) Insect herbivore nutrient regulation. Annu. Rev. Entomol. 54, 165-187

Bischoff, H. (1927) Biologie der Hymenopteren. Biologische Studienbücher V. Springer Verlag, Berlin

Blacquiere, T., Smagghe, G., Van Gestel, C.A., Mommaerts, V. (2012) Neonicotinoids in bees: a review on concentrations, side-effects and risk assessment. Ecotoxicology 21, 973-992

Bohart, G.E., Cross, E.A. (1955) Time relationships in the nest construction and life cycle of the alkali bee. Ann. Entomol. Soc. Amer. 48, 403-406

Bohart, G.E., Lieberman, F.V. (1949) Effect of An Experimental Field Application of DDT Dust on Nomia melanderi. J. Econ. Entomol. 42, 519-522

Brunner, F.S., Schmid-Hempel, P., Barribeau, S.M. (2014) Protein-poor diet reduces host-specific immune gene expression in Bombus terrestris. Proc. Roy. Soc. B Biol. 281, 1-10

Camargo, J.M.F., Gottsberger, G., Silberbauer-Gottsberger, I. (1984) On the phenology and flower visiting behavior of Oxaea flavescens (Klug) (Oxaeinae, Andrenidae, Hymenoptera) in Sao Paulo. Brazil. Beitr. Biol. Pflanzen 59, 159-179

Cameron, S.A., Whitfield, J.B., Hulslander, C.L., Cresko, W.A., Isenberg, S.B., et al. (1996) Nesting biology and foraging patterns of the solitary bee Melissodes rustica (Hymenoptera: Apidae) in northwest Arkansas. J. Kansas Entomol. Soc. 69, 260-273

Cane, J.H. (1981) Dufour's gland secretion in the cell linings of bees (Hymenoptera: Apoidea). J. Chem. Ecol. 7, 403-410
Cane, J.H. (2002) Pollinating bees (Hymenoptera: Apiformes) of U.S. alfalfa compared for rates of pod and seed set. J. Econ. Entomol. 95, 22-27

Cane, J.H. (2008) A native ground-nesting bee (Nomia melanderi) sustainably managed to pollinate alfalfa across an intensively agricultural landscape. Apidologie 39, 315-323

Cane, J.H., Carlson, R. (1984) Dufour's gland glycerides from Anthophora, Emphoropsis (Anthophoridae) and Megachile (Megachilidae) bees (Hymenoptera: Apoidea). Comp. Biochem. Physiol. 78B , 769-772

Crailsheim, K., Schneider, L.H.W., Hrassnigg, N., Bühlmann, G., Broasch, U., et al. (1992) Pollen consumption and utilization in worker honeybees (Apis mellifera carnica ): dependence on individual age and function. J. Insect Physiol. 38, 409-419

Danforth, B.N. (1989) Nesting behavior of four species of Perdita (Hymenoptera: Andrenidae). J. Kansas Entomol. Soc. 62 (1), 59-79

Danforth, B.N. (1990) Provisioning behavior and the estimation of investment ratios in a solitary bee, Calliopsis (Hypomacrotera) persimilis (Cockerell) (Hymenoptera: Andrenidae). Behav. Ecol. Sociobiol. 27, 159168

Danforth, B.N. (1991) Female foraging and intranest behavior of a communal bee, Perdita portalis (Hymenoptera: Andrenidae). Ann. Entomol. Soc. Amer. 84, 537-548

Dietz, A. (1969) Initiation of pollen consumption and pollen movement through the alimentary canal of newly emerged honey bees. Ann. Entomol. Soc. Am. 62, 43-46. 1969

Dietz A. (1975) Nutrition of the adult honey bee. In: R.A. Grout (Ed.), The Hive and the Honey Bee. Dadant and Sons, Inc., Carthage, Illinois, pp 125-156

Gerling, D., Hermann, H.R. (1978) Biology and mating behavior of Xylocopa virginica L. (Hymenoptera, Anthophoridae). Behav. Ecol. Sociobiol. 3, 99-111

Giurgius, G.N., Brindley, W.A. (1974) Insecticide susceptibility and response to selected pollens of larval alfalfa leafcutting bees, Megachile pacifica (Panzer) (Hymenoptera: Megachilidae). Environ. Entomol. 3 , 691-694

Goulson, D. (2003) The conservation of bumble bees. Bee World 84, 105-106

Hodgson, E.W., Pitts-Singer, T.L., Barbour, J.D. (2011) Effects of the insect growth regulator, novaluron on immature alfalfa leafcutting bees, Megachile rotundata. J. Insect Sci. 11, 43

Hrassnigg, N., Crailsheim, K. (1998) The influence of brood on the pollen consumption of worker bees (Apis mellifera L.). J Insect Physiol 44, 393-404

Isenberg, S.B., Cameron, S.A., Whitfield, J.B. (1997) Crop storage of pollen and its functional significance in the solitary bee, Melissodes rustica (Hymenoptera: Apidae). J. Kansas Entomol. Soc. 70, 353-358

Iwata, I., Sakagami, S.F. (1966) Gigantism and dwarfism in bee eggs in relation to the modes of life, with notes on the number of ovarioles. Jpn. J. Ecol. 16, 4-16 
Jander, R. (1976) Grooming and pollen manipulation in bees (Apoidea): the nature and evolution of movements involving the foreleg. Physiol. Entomol. 1, 179-194

Käpylä M. (1978) Bionomics of five wood-nesting solitary species of bees (Hym., Megachilidae), with emphasis on flower relationships. Biol. Res. Rep. Univ. Jyväskylä 5, 3-89

Klostermeyer, E.C., Gerber, H.S. (1969) Nesting behavior of Megachile rotundata (Hymenoptera: Megachilidae) monitored with an event recorder. Ann. Entomol. Soc. Amer. 62 , 1321-1326

Kugler, H. (1970) Blütenökologie, 2nd edn. Gustav Fischer Verlag, Stuttgart

Lind, H. (1968) Nest-provisioning cycle and daily routine of behaviour in Dasypoda plumipes (Hym., Apidae). Entomol. Meddeleser 36, 343-372

Maeta, Y., Kitamura, T. (2005) On the number of eggs laid by one individual of females in the Alfalfa LeafCutting Bee, Megachile (Eutricharaea) rotundata (Fabricius) (Hymenoptera, Megachilidae). Chugoku Kontyu 19, 39-43

Mao, W., Schuler, M.A., Berenbaum, M.R. (2013) Honey constituents up-regulate detoxification and immunity genes in the western honey bee Apis mellifera. Proc. Natl. Acad. Sci. 110, 8842-8846

Michener C.D. (1974) The social behavior of the bees: a comparative study. Harvard University of Press, Cambridge, Massachusetts

Michener, C.D. (2007) The bees of the world. Johns Hopkins Univ. Press, Baltimore

Neff, J.L. (2008) Components of nest provisioning behavior in solitary bees (Hymenoptera: Apoidea). Apidologie 39, 30-45

Norden, B., Batra, S.W.T., Fales, H.F., Hefetz, A., Shaw, G.J. (1980) Anthophora bees: unusual glycerides from maternal Dufour's glands serve as larval food and cell lining. Science 207, 1095-1097

Ordway, E. (1966) Systematics of the genus Augochlorella (Hymenoptera: Halictidae) north of Mexico. Univ. Kansas Sci. Bull. 46, 509-624

Peng, Y.S., Nasr, M.E., Marston, J.M. (1986) Release of alfalfa (Medicago sativa) pollen cytoplasm in the gut of the honeybee (Apis mellifera) (Hymenoptera: Apidae). Ann. Entomol. Soc. Amer. 79, 804-807

Phillips, J.K., Klostermeyer, E.C. (1978) Nesting behavior of Osmia lignaria propinqua Cresson (Hymenoptera: Megachilidae). J. Kansas Entomol. Soc. 51, 91-108

Rezkova, K., Zakova, M., Zakova, Z., Straka, J. (2012) Analysis of nesting behavior based on daily observation of Andrena vaga (Hymenoptera: Andrenidae). J. Insect Behav. 25, 24-47

Richards, K.W. (1994) Ovarian development in the alfalfa leafcutter bee, Megachile rotundata. J. Apic. Res. 33, 199-203

Roberts, R.B. (1969) Biology of the bee genus Agapostemon (Hymenoptera: Halictidae). Univ. Kansas Sci. Bull. 48, 689-719
Roulston, T.H., Cane, J.H. (2000) Pollen nutritional content and digestibility for animals. Plant Syst. Evol. 222, 187-209

Sandrock, C., Tanadini, L.G., Pettis, J.S., Biesmeijer, J.C., Potts, S.G., et al. (2014) Sublethal neonicotinoid insecticide exposure reduces solitary bee reproductive success. Agric. Forest Entomol. 16, 119-128

Schäffler, I., Dötterl, S. (2011) A day in the life of an oil bee: phenology, nesting, and foraging behavior. Apidologie 42, 409-424

Schmidt, J.O., Buchmann, S.L. (1985) Pollen digestion and nitrogen utilization by Apis mellifera L. (Hymenoptera: Apidae). Comp. Biochem. Physiol. 82A, 499-503

Schremmer, F. (1972) Der stechsaugrüssel, der nektarraub, das pollensammeln und der blütenbesuch der holzbienen (Xylocopa) (Hymenoptera, Apidae). Zeit. Morphol. Tiere 72, 263-294

Szolderits, M.J., Crailsheim, K. (1993) A comparison of pollen consumption and digestion in honeybee (Apis mellifera carnica) drones and workers. J. Insect Physiol. 39, 877-881

Taniguchi, S. (1956) Biological studies on the Japanese bees. III. Request in flower-visiting of infrasocial bees. Sci. Rep. Hyogo Univ. Agric. Ser. Agric. Biol. 2 , 37-51

Thorp, R.W. (2000) The collection of pollen by bees. Plant Syst. Evol. 222 , 211-223

Ueira-Vieira C., Nunes-Silva C.G., Absy M.L., Pinto M.D.F.D., Kerr W.E. and others (2013) Pollen diversity and pollen ingestion in an Amazonian stingless bee, Melipona seminigra (Hymenoptera, Apidae). J. Apic. Res. 52, 173-178

Visscher, P.K., Danforth, B.N. (1993) Biology of Calliopsis pugionis (Hymenoptera: Andrenidae): nesting, foraging, and investment sex ratio. Ann. Entomol. Soc. Amer. 86, 822-832

Waldbauer, G.P., Friedman, S. (1991) Self-selection of optimal diets by insects. Annu. Rev. Entomol. 36, 43-63

Waller, G.D. (1969) Susceptibility of an alfalfa leafcutting bee to residues of insecticides on foliage. J. Econ. Entomol. 62, 189-192

Wang, H., Zhang, S.W., Zeng, Z.J., Yan, W.Y. (2014) Nutrition affects longevity and gene expression in honey bee (Apis mellifera) workers. Apidologie 45, 618-625

Wheeler, D. (1996) The role of nourishment in oogenesis. Annu. Rev. Entomol. 41, 407-431

Whitcomb W.J., Wilson H.F. (1929) Mechanics of digestion of pollen by the adult honey bee and relation of undigested parts to dysentery of bees. Res. Bull. Agric. Exper. Station, Univ. Wisconsin 92, 27

Wuellner, C.T. (1999) Nest site preference and success in a gregarious, ground-nesting bee Dieunomia triangulifera. Ecol. Entomol. 24, 471-479

Zerbo, A.D., de Moraes, R.L.M.S., Brochetto-Braga, M.R. (2001) Protein requirements in larvae and adults of Scaptotrigona postica (Hymenoptera: Apidia, Meliponinae): midgut proteolytic activity and pollen digestion. Comp. Biochem. Physiol. B-Biochem. Mol. Biol. 129, 139-147 